\title{
Isolation and Characterization of Xanthobacter polyaromaticivorans sp. nov. 127W That Degrades Polycyclic and Heterocyclic Aromatic Compounds under Extremely Low Oxygen Conditions
}

\author{
Shin-ichi Hirano, ${ }^{1}$ Fumiya Kitauchi, ${ }^{1, *}$ Mitsuru Haruki, ${ }^{1, * *}$ Tadayuki Imanaka, ${ }^{2}$ \\ Masaaki Morikawa, ${ }^{1, \dagger}$ and Shigenori KANAYA ${ }^{1}$ \\ ${ }^{1}$ Department of Material and Life Science, Graduate School of Engineering, Osaka University, \\ Suita, Osaka 565-0871, Japan \\ ${ }^{2}$ Department of Synthetic Chemistry and Biological Chemistry, Graduate School of Engineering, \\ Kyoto University, Kyoto 615-8510, Japan
}

Received August 20, 2003; Accepted November 27, 2003

Two bacterial strains, $127 \mathrm{~W}$ and $\mathrm{T} 102$, were isolated from anoxic crude oil tank sludge as effective degraders of dibenzothiophene (DBT), a model sulfur containing heterocyclic aromatic compound in crude oil. Strain 127W was more tolerant to oxygen limitation than T102 and was capable of degrading two- and three-ring polycyclic and heterocyclic aromatic compounds under both aerobic and low oxygen conditions. Strain 127W degraded $0.082,0.055$, and $0.064 \mathrm{mM}$ of DBT, naphthalene, and anthracene, respectively, in one week with dissolved oxygen $</=0.2 \mathrm{ppm}(0.006 \mathrm{~mm})$. Degradation by $127 \mathrm{~W}$ cell-free extracts for DBT was increased by addition of sodium hydrogencarbonate under this oxygen concentration. Phylogenetic analysis of the $16 \mathrm{~S}$ rRNA gene sequence and physiological characteristics indicate that the strains $127 \mathrm{~W}$ and T102 belong to new species of the genus Xanthobacter and Pseudomonas stutzeri, respectively. We propose $X$. polyaromaticivorans sp. nov. $127 \mathrm{~W}$.

Key words: Xanthobacter polyaromaticivornas; polycyclic aromatic hydrocarbons; heterocyclic aromatic compounds; extremely low oxygen; degradation

Contamination by polycyclic aromatic hydrocarbons (PAHs) and heterocyclic aromatic compounds (HACs) is of great environmental concern because of their toxic, mutagenic, and carcinogenic properties. ${ }^{1,2)}$ The fate of hydrocarbons and other organic contaminants in environments is associated with both abiotic and biotic processes, including volatilization, photo-oxidation, chemical oxidation, bioaccumulation, and microbial transformation. These PAHs and HACs are actually persistent, mainly due to their low water solubility. Nevertheless, various bacteria and fungi can degrade certain PAHs and HACs, and microbial activity has been regarded the most influential and significant cause of their removal. ${ }^{3-6)}$ Although PAH (especially naphthalene) degradations by bacteria have been extensively studied, ${ }^{3)}$ little information is yet available on the degradation by pure cultures under low oxygen or anaerobic conditions, reflecting the importance of oxygen as an electron acceptor for PAH degradation by most bacteria. ${ }^{7}$ Although PAHs and HACs in surface waters or soil particles are susceptible to degradation by various aerobic bacteria, large fraction of PAHs and HACs stick to solid particles and settle to the bottoms of rivers or lakes where only limited oxygen is available. ${ }^{8)}$ These fractions remain un-degraded for long periods because anaerobic biodegradation proceeds slowly. Even the polluted site soon becomes anoxic due to the high oxygen demand for hydrocarbon degradation by bacteria. There is thus a significant interest in isolating and studying microorganisms that effectively degrade PAHs and HACs under low oxygen conditions from viewpoints of developing bioremediation and natural attenuation technologies. Because PAHs and HACs are abundantly contained in the crude oil, we chose anoxic sludge in crude oil reservoir tanks as a promising source for isolating such bacteria. Degradation of HAC is less understood than PAH and we adopted dibenzothiophene (DBT), which is a typical HAC in crude oil, as a substrate for isolating bacteria. Here, we report the isolation and characterization of two bacterial strains, T102 and $127 \mathrm{~W}$, that are capable of degrading DBT under low oxygen conditions. Strain $127 \mathrm{~W}$ revealed unique preference for carbon sources including hydro-

\footnotetext{
To whom correspondence should be addressed. Tel/Fax: +81-6-6879-7443; E-mail: morikawa@mls.eng.osaka-u.ac.jp

* Present address: Medical Products Division, UNITIKA Ltd. Chuo-ku, Osaka 541-8566, Japan

** Present address: Department of Materials Chemistry and Engineering, College of Engineering, Nihon University, Koriyama, Fukushima $963-$ 8642, Japan
} 
carbons and significant tolerance to low oxygen conditions. We propose Xanthobacter polyaromaticivorans $127 \mathrm{~W}$ sp. nov.

\section{Materials and Methods}

Chemicals. DBT, naphthalene, and biphenyl were purchased from WAKO Pure Chemicals (Osaka, Japan). Anthracene, 2- or 9-chloroanthracene, 2-methylanthracene, pyrene, dibenzodioxine, dibenzofuran, fluorene, and phenanthrene were purchased from Tokyo Kasei Co. (Tokyo, Japan). 4,6-dimethyl dibenzothiophene was a gift from the Petroleum Energy Center (PEC, Tokyo, Japan).

Media and culture conditions. Carbon-free and sulfurfree (CSF) medium was used for bacterial isolation and PAH or HAC-degradation experiments. CSF medium contained per liter, $4 \mathrm{~g}$ of $\mathrm{K}_{2} \mathrm{HPO}_{4}, 4 \mathrm{~g}$ of $\mathrm{Na}_{2} \mathrm{HPO}_{4}, 2 \mathrm{~g}$ of $\mathrm{NH}_{4} \mathrm{NO}_{3}, 0.01 \mathrm{~g}$ each of $\mathrm{MgCl}_{2} \cdot 6 \mathrm{H}_{2} \mathrm{O}, \mathrm{CaCl}_{2} \cdot 2 \mathrm{H}_{2} \mathrm{O}$, and $\mathrm{FeCl}_{2} \cdot 2 \mathrm{H}_{2} \mathrm{O}$, and the $\mathrm{pH}$ was adjusted to 7.0. DBT, which is one of the typical HACs, was used as sole carbon and sulfur sources for initial screening of bacteria. CSFY medium, in which $0.05 \mathrm{~g} / l$ of yeast extract was added to CSF medium, was also used for the degradation test. L broth containing per liter, $5 \mathrm{~g}$ of yeast extract, $5 \mathrm{~g}$ of $\mathrm{NaCl}$, and $10 \mathrm{~g}$ of Bacto tryptone ( $\mathrm{pH} 7.2$ ) was used for maintaining cells. All PAHs and HACs used in this study were crystalline solids at room temperature. For the preparation of stock solution, each compound was dissolved in ethanol. The stock solution was added to a sterilized medium at a final concentration of $0.1 \mathrm{~mm}$ otherwise denoted. Cultivation was done at $30^{\circ} \mathrm{C}$ under either aerobic $(7 \mathrm{ppm}<\mathrm{DO}$, dissolved oxygen concentration) or low oxygen conditions (DO $</=7 \mathrm{ppm})$. For the plate culture the CSF medium was solidified with $1.5 \%$ agar and $100 \mu \mathrm{l}$ of $0.1 \mathrm{~mm}$ DBT ethanol solution was overlaid on the surface. The degradation activity of DBT was detected as both the stable growth of the cells and formation of a colored clear zone around the colony. ${ }^{9,10)}$

Low oxygen conditions. Low oxygen conditions were prepared as follows; bottles or plates containing medium and a PAH or a HAC were left in the anaerobic chamber (EAN-101, Tabai Espec, Osaka, Japan) for a defined time after degassing twice by $\mathrm{N}_{2}$ gas and once by the guaranteed anaerobic gas mixture $\left(\mathrm{CO}_{2} / \mathrm{H}_{2} / \mathrm{N}_{2}=\right.$ 5:5:90 with $\mathrm{DO}<0.02 \mathrm{ppm})$. Trace oxygen contamination if any, was continuously removed by Pd-Al catalyst and silica gels. DO in the medium decreased as the length of the time kept in the anaerobic chamber increased. After $24 \mathrm{hr}$, DO decreased to $</=0.2 \mathrm{ppm}$. Culture media with different DO were prepared by changing the length of the time kept in the anaerobic chamber. ${ }^{11)}$

Monitoring of dissolved oxygen. DO in the media and culture was monitored using DO meter (type B-505/ GU-B7; Iijima electronic Co., Ltd.) with a dynamic range from 0 to $20 \mathrm{mg} / l$ (ppm) oxygen and an accuracy of $+/-0.2 \%$. Standard DO in water saturated with air (1 atom) was $9.1 \mathrm{mg} / l(9.1 \mathrm{ppm})$ at $20^{\circ} \mathrm{C}$.

Degradation test of PAHs and HACs. Exponentially growing cultures in $\mathrm{L}$ broth were harvested by centrifugation at $10,000 \times g$ for $10 \mathrm{~min}$ at $4^{\circ} \mathrm{C}$. Cells were washed once with sterile water and suspended in a small amount of water. The CSF or CSFY medium containing $0.1 \mathrm{~mm}$ PAH or HAC was inoculated with the cell suspension at a final $\mathrm{OD}_{660}$ of 5 unless otherwise denoted. The vial bottles containing this reaction mixture were tightly sealed with butyl rubber septa with aluminum crimps, and stood at $30^{\circ} \mathrm{C}$ for one week.

Extraction of PAHs and HACs and gas chromatography $(G C)$. The reaction mixture was acidified to $\mathrm{pH}$ 2.0 with $6 \mathrm{M} \mathrm{HCl}$ and the PAH or $\mathrm{HAC}$ was extracted with one volume of ethylacetate containing $0.12 \mathrm{mM}$ of fluorene or phenanthrene as an internal standard. In order to eliminate trace contamination with air and absorption of hydrocarbons to the butyl rubber stopper, we neither used a needle to take samples from the bottle nor transferred samples to another bottle. Instead, the whole the reaction mixture in the bottle was directly extracted in the original bottle at each reaction time. Every sample was prepared in triplicate together with a negative control containing no cells. A portion of the ethylacetate layer was analyzed by GC system HP6890, which was equipped with a 30-m non-polar capillary column HP-1 (Hewlett Packard, Palo Alto, CA) and a FID detector (GC/FID) or JEOL JMS-DX303 mass spectrometer (JEOL, Tokyo, Japan, GC/MS). The operating conditions were briefly as follows; oven temperature was linearly increased from 80 to $300^{\circ} \mathrm{C}$ at a rate of $10^{\circ} \mathrm{C} / \mathrm{min}$ and an injection volume of the sample was $1 \mu \mathrm{l}$ with a split ratio of $50: 1^{12)}$ Temperatures for injector and detector were both set at $250^{\circ} \mathrm{C}$.

Isolation and sequencing of 16S rRNA gene. Genomic DNA was prepared and purified from late-exponential phase cells of strain $127 \mathrm{~W}$ or $\mathrm{T} 102$ by CsCl-density gradient ultra-centrifugation. ${ }^{13)}$ Polymerase chain reaction (PCR) was done by using $100 \mathrm{ng}$ of genomic DNA and one unit of KOD polymerase (Toyobo, Osaka, Japan) with forward and reverse primers which corresponded to nucleotide positions 7 to 23 (5'-AAGAGTTTGATCATGGC-3') and 1510 to $1492\left(5^{\prime}-\right.$ GGTTACCTTGTTACGACTT-3'), respectively, of the Escherichia coli 16S rRNA gene (EMBL/GenBank/ DDBJ accession number X80721) as described elsewhere. The resulting $1.5 \mathrm{~kb}$ PCR products were analyzed by agarose gel electrophoresis and purified with a GeneClean kit (Bio101 Inc., La Jolla, CA). Purified DNA fragment was cloned in pUC18 at SmaI site. The nucleotide sequence of the $16 \mathrm{~S}$ rRNA gene was 
analyzed for both strands by the dideoxy chain termination method with an ABI PRISM 310 genetic analyzer (Applied Biosystems Japan, Tokyo, Japan).

Phylogenetic analysis. A phylogenetic tree based on the distance matrix of $16 \mathrm{~S}$ rRNA gene sequences of $127 \mathrm{~W}$ and related strains in the alpha subclass of proteobacteria was constructed by using the TreeView program. ${ }^{14)}$ The BLAST $\mathrm{N}$ program (http:// www.ncbi.nlm.nih.gov/BLAST/, NCBI) was used for searching for homologous genes with the standard program default and the nucleotide sequences were obtained from the EMBL/GenBank/DDBJ database. The nucleotide sequence region containing " $\mathrm{N}$ ", an unidentified base, was eliminated before constructing multiple alignment and a distance matrix by the ClustalW program ${ }^{15)}$ (http://clustalw.genome.ad.jp/).

Nucleotide sequence accession numbers. The following 16S rRNA gene sequences were retrieved from DDBJ/GenBank/EMBL (accession numbers are given in parenthesis) to construct a phylogenetic tree: Xanthobacter sp. INA43/2-2 (AJ306541), X. autotrophicus (X94201), Monochloacetic acid degrading bacterium MCAA1 (AF532187), X. tagetidis (X99469), X. flavus (X94204), X. agilis (X94198), Azorhizobium sp. Br5401 (AF391130), A. caulinodans (X94200), alpha proteobacterium 76712 (AF288311), Methylocystis echinoides (AJ458473), Methylosinus trichosporium (AJ458491), Defluvibacter lusatiae (AJ132378), Shinorhizobium sp. C9 (AF227756), Mesorhizobium amorphae (AJ271899), Mesorhizobium sp. SH2851 (AY141983), Rhizobium ciceri (U07934), Phyllobacteriaceae bacterium NL21 (AF534573), Rhodospirillum rubrum (D30778). $R$. rubrum was used as a representative member of an out-group of the tree. The nucleotide sequences of the $16 \mathrm{~S}$ rRNA genes of strains $127 \mathrm{~W}$ and T102 have been deposited under accession numbers AB106864 and AB098613, respectively.

Physiological characterization of the strains. Characterization of $127 \mathrm{~W}$ and T102 was done according to Bergey's Manual of Systematic Bacteriology ${ }^{16)}$ and by using the API $20 \mathrm{E}^{\mathrm{TM}}$ system (bioMeriux Japan Ltd., Tokyo, Japan).

Mol\% GC content. The base composition of the genomic DNA was identified by the HPLC method after P1 nuclease (Yamasa Shoyu, Chiba, Japan) and alkaline phosphatase (Takara. Bio inc., Kyoto, Japan) treatments as previously reported. ${ }^{17)}$ Concentrations of $\left(\mathrm{NH}_{4}\right)$ $\mathrm{H}_{2} \mathrm{PO}_{4}$ buffer and DNA were modified to $20 \mathrm{mM}$ and $500 \mathrm{ng} / \mathrm{ml}$, respectively. The equimolar mixture of four dNTPs (Yamasa Shoyu) and genomic DNA samples from E. coli JM109, B. subtilis MI113, and Haemophilus parainfluenzae IID 991were used as standard references. were treated with $\mathrm{Pt} / \mathrm{Pd}$ shadowing on a collodion membrane and observed with a scanning electron microscope model JEM-200CX (JEOL, Tokyo, Japan).

\section{Results and Discussion}

\section{Isolation of DBT degrading bacteria}

Anoxic sludge samples from crude oil tank reservoirs were either made into an enrichment culture or directly streaked on the CSF solid medium supplemented with DBT (0.1 mM) as sole carbon and sulfur sources. The plate cultures were incubated at $30^{\circ} \mathrm{C}$ for several days in an anaerobic chamber. Colonies were picked up and transferred to new plates several times to confirm their stable cell growth. Forty-three strains were isolated as DBT degrading bacteria in the initial screening. Finally, two strains, $127 \mathrm{~W}$ and T102, were selected as effective DBT degraders under low oxygen conditions. Low oxygen conditions were defined as the condition at initial DO $<7 \mathrm{ppm}$ and an Extremely Low Oxygen (ELO) condition was defined as $\mathrm{DO}</=0.2 \mathrm{ppm}$. Strains $127 \mathrm{~W}$ and T102 were isolated from sludge in crude oil reservoir tanks in Fukui and Okinawa, Japan, respectively.

Effects of dissolved oxygen concentration on DBT degradation

The DBT degradation ability of each strain was compared under various oxygen concentrations (Fig. 1). Under aerobic condition, strains $127 \mathrm{~W}$ and T102 degraded $0.55 \mathrm{~mm}$ and $0.38 \mathrm{~mm}$ of DBT in a week, respectively. When DBT degradation was examined under low oxygen conditions, strain T102 degraded $0.23 \mathrm{~mm}$ of DBT at a DO condition of $6.7 \mathrm{ppm}$ but did not degrade DBT at DO conditions lower than $5 \mathrm{ppm}$. Strain $127 \mathrm{~W}$ degraded $0.07 \mathrm{~mm}$ DBT even under the ELO condition ( $\mathrm{DO}</=0.2 \mathrm{ppm}$ ). These results indicate that the degradation ability of strain $127 \mathrm{~W}$ is significantly tolerant to oxygen limitation. Strain $127 \mathrm{~W}$ was then used for further analyses. Because the DBT degradation experiments were done in securely closed vials, the amount of oxygen available for degradation in the reaction mixture was calculated from initial DO and compared it with the amount of DBT degraded by strain $127 \mathrm{~W}$ (Table 1). The amount of DBT degraded was directly correlated to the DO values higher than or equal to $2.7 \mathrm{ppm}(0.08 \mathrm{~mm})$. This observation suggests that dissolved oxygen is the limiting factor and one mole of oxygen is required for the degradation of one mole DBT, and also suggests that an oxygenase-like enzyme is involved in DBT degradation. However strain $127 \mathrm{~W}$ degraded $0.07 \mathrm{~mm}$ DBT at DO conditions $</=0.2 \mathrm{ppm}$ $(0.006 \mathrm{~mm})$. This result may suggest that $127 \mathrm{~W}$ uses an alternative degradation pathway under ELO conditions although no degradation was observed under strictly the anaerobic condition. 
(a)

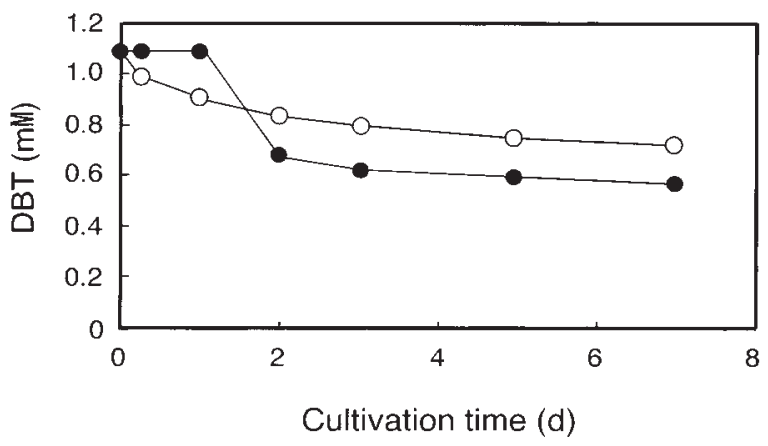

(b)

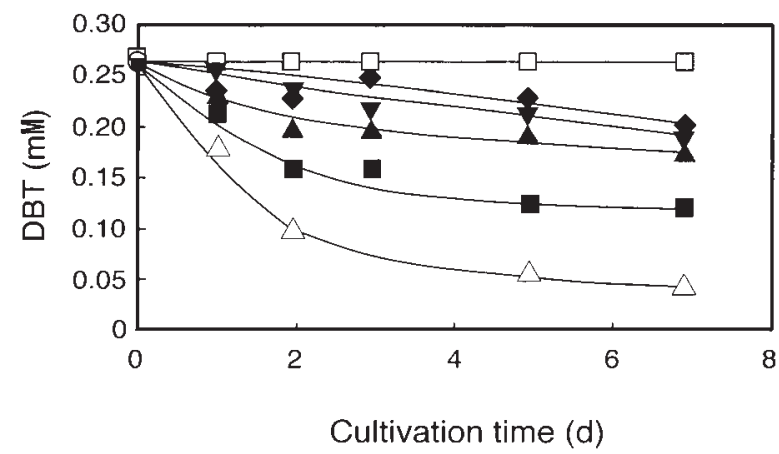

Fig. 1. Degradation of DBT by Strains $127 \mathrm{~W}$ and T102.

Cells were inoculated at $\mathrm{OD}_{660}$ of 0.08 and cultivated at $30^{\circ} \mathrm{C}$ for one week in CSF medium supplemented with DBT at a final concentration of $200 \mathrm{ppm}(1.09 \mathrm{~mm}$, a) and $50 \mathrm{ppm}(0.27 \mathrm{~mm}, \mathrm{~b})$. Remaining DBT was extracted with ethylacetate and quantified from the peak area in GC/FID analysis. Data are mean values of three independent experiments after subtraction of that with no cell inoculation. (a) DBT degradation under aerobic condition (DO $>7 \mathrm{ppm}$ ) by $\mathrm{O}, 127 \mathrm{~W}$ and $\mathrm{O}$, T102. (b) DBT degradation by $127 \mathrm{~W}$ under low oxygen conditions. DO: $\boldsymbol{\square}, 4.9 \mathrm{ppm} ; \boldsymbol{\Delta}$, $3.1 \mathrm{ppm} ; \boldsymbol{\nabla}, 2.7 \mathrm{ppm} ; \boldsymbol{\diamond}, 0.2 \mathrm{ppm}$. No degradation activity was observed for T102 under these conditions, and only the data obtained at the DO of $6.7 \mathrm{ppm}, \triangle$, and $4.9 \mathrm{ppm}, \square$, are shown.

Table 1. Relationships between DO and DBT Degradation by $127 \mathrm{~W}$

\begin{tabular}{clc}
\hline \hline $\begin{array}{c}\text { DO } \\
(\mathrm{ppm})\end{array}$ & $\begin{array}{c}\text { DO } \\
(\mathrm{mM})\end{array}$ & $\begin{array}{c}\text { Degraded DO } \\
(\mathrm{mm})\end{array}$ \\
\hline 4.9 & 0.15 & $0.14 \pm 0.014$ \\
3.1 & 0.10 & $0.09 \pm 0.013$ \\
2.7 & 0.08 & $0.08 \pm 0.017$ \\
0.2 & 0.006 & $0.07 \pm 0.012$ \\
\hline
\end{tabular}

\section{Degradation products of DBT in the strains $127 \mathrm{~W}$ and} T102

In order to shed light on the aerobic degradation pathways of DBT by strains $127 \mathrm{~W}$ and T102, ethylacetate extractable fractions were prepared from the spent media at appropriate times after inoculation to CSFY $\left(\mathrm{OD}_{660}=0.1\right)$ containing $0.5 \mathrm{~mm}$ DBT and analyzed by GC/FID and GC/MS. In both strains, a possible DBT degradation product and un-degraded DBT were detected as single peaks at 12-min and 21min, respectively (data not shown). The height of the 12 min peak increased as that of 21 min peak decreased. $\mathrm{GC} / \mathrm{MS}$ analysis of this peak fraction showed molecular and fragment ions at $m / z=178\left(\mathrm{M}^{+}\right), 160\left(\mathrm{M}^{+}-\mathrm{H}_{2} \mathrm{O}\right)$, $150\left(\mathrm{M}^{+}-\mathrm{CO}\right), 149\left(\mathrm{M}^{+}-\mathrm{CHO}\right), 132\left(\mathrm{M}^{+}-\mathrm{H}_{2} \mathrm{O}-\mathrm{CO}\right)$. These data strongly suggest that this compound is 3hydroxy-2-formylbenzothiophene (3H2FBT) derived from DBT. 3H2FBT is one of the most popular intermediates in the DBT degradation pathway, the Kodama pathway, of Pseudomonas strains in which DBT 2,3-dioxygenase is involved. ${ }^{18,19)}$

Possibility of oxygen-independent degradation of DBT by the strain $127 \mathrm{~W}$

It was shown that $127 \mathrm{~W}$ effectively degraded DBT under low oxygen conditions (Fig. 1b, Table 1). This suggests that an electron acceptor other than oxygen functions in the low oxygen condition. Both $\mathrm{NO}_{3}{ }^{-}$and $\mathrm{Fe}^{3+}$ in the media, which are potential electron acceptors, were shown to be not essential for degradation of DBT by $127 \mathrm{~W}$ at ELO condition (data not shown). In contrast, addition of sodium hydrogencarbonate $\left(\mathrm{NaHCO}_{3}\right)$ in the reaction mixture increased degradation of DBT by using cell-free extracts of $127 \mathrm{~W}$ (Fig. 2). The residual amount of DBT was decreased until $1 \mathrm{hr}$ upon incubation and was kept unchanged until $6 \mathrm{hr}$. Although further studies are necessary to conclude that $\mathrm{HCO}_{3}{ }^{-}$or $\mathrm{CO}_{3}{ }^{2-}$ functions as an electron acceptor or carboxylation of DBT is involved in the degradation, it would play some important role at the ELO condition. Anaerobic degradation of benzothiophene by a sulfate-reducing enrichment culture has been reported and several carboxylated compounds were identified as degradation intermediates. ${ }^{20)}$ Denitrifying bacteria, such as Thauera aromatica, have been reported to degrade monoaromatic hydrocarbons through a pathway of forming benzoyl$\mathrm{CoA}$ and an initial carboxylation by $\mathrm{CO}_{2}$ is also suggested. ${ }^{21)}$

\section{Degradation of PAHs and HACs by strain $127 \mathrm{~W}$}

Degradation ability of $127 \mathrm{~W}$ was tested for various PAHs and HACs under both aerobic and ELO conditions (Fig. 3). The strain degraded 0.082, 0.055, 0.064, and $0.015 \mathrm{mM}$ of DBT, naphthalene, anthracene, and phenanthrene, respectively at the ELO condition. However, it did not degrade a four-ring aromatic compound pyrene even under aerobic conditions. We do not know why dibenzofuran was much less degraded than DBT under the ELO condition. The strain also degraded biphenyl and 9-chloroanthracene but did not degrade 4, 6-dimethyl dibenzothiophene, dibenzodioxine, 2-methylanthracene, or 2-chloroanthracene. These substrate preferences suggest that external ring attack is the initial oxidation step by $127 \mathrm{~W}$.

There are several reports available for anaerobic degradation of naphthalene and phenanthrene by using 


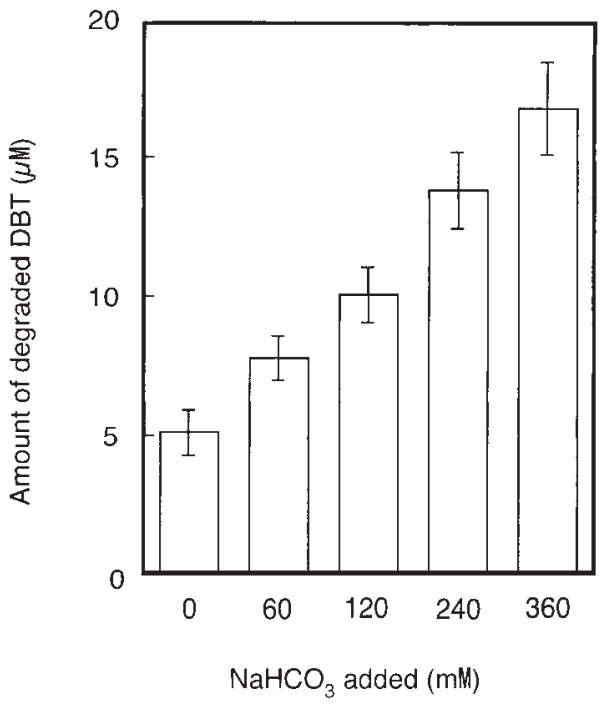

Fig. 2. Effect of $\mathrm{NaHCO}_{3}$ on the ELO Degradation of DBT.

A degradation test was done according to the Materials and Methods with the following modifications. Cells $\left(\mathrm{OD}_{660} ; 0.1\right)$ were grown for 3 days in CSFY containing 0.1 mM DBT and disrupted by sonication in the anaerobic chamber to prepare cell-free extracts for degradation reactions. This enabled us to neglect the effects of carbonate on the viability or growth of the cells. The reaction mixture contained $50 \mathrm{~mm}$ Tris- $\mathrm{HCl}$ ( $\mathrm{pH} 7.5$ ), $10 \mathrm{~mm}$ of ATP, $5 \mathrm{~mm}$ of $\mathrm{MgCl}_{2}, 0.5 \mathrm{mM}$ of $\mathrm{MnCl}_{2}$ and $100 \mu \mathrm{M}$ each of biotin, thiamin pyrophosphate, pyridoxal 5-phosphate, and appropriate amount of $\mathrm{NaHCO}_{3}$. The mixture was left in the anaerobic chamber for $24 \mathrm{hr}$ and the DO was confirmed to be lower than or equal to $0.2 \mathrm{ppm}$. Finally, $0.1 \mathrm{~mm}$ of DBT, which had been kept in the anaerobic chamber, and $0.5 \mathrm{mg} / \mathrm{ml}$ of the cell-free extracts from $127 \mathrm{~W}$ cells were added to the mixture to initiate the degradation reaction. The degradation reaction was done at $30^{\circ} \mathrm{C}$ for $2 \mathrm{hr}$. Extraction and GC quantification of the remaining DBT was done as described in Materials and Methods. Data are mean values of three independent reactions after subtraction of that with no cell extracts. The bars indicate standard deviations (S.D.). enrichment culture or sediment samples from contaminated sites. Sediment samples from hydrocarbon contaminated sites in San Diego Bay degraded more than $0.05 \mathrm{~mm}$ of naphthalene in 30 days incubation at $25^{\circ} \mathrm{C}$ under sulfate-reducing condition. ${ }^{22)}$ An anaerobic enrichment culture from New York/New Jersey harbor degraded 0.07 to $0.1 \mathrm{~mm}$ naphthalene and $c a .0 .07 \mathrm{~mm}$ phenanthrene in 14 days at $30^{\circ} \mathrm{C}$. Carboxylation of the substrate was suggested for the initial degradation reaction in this case. ${ }^{23)}$ Under the nitrate reduction condition, a fuel-contaminated Arctic soil sample was shown to degrade 0.02 to $0.04 \mathrm{mg} / 1 \mathrm{PAHs}$ in 40 days at both 20 and $7^{\circ} \mathrm{C} .{ }^{24)}$ Recently, a significant amount of DBT degradation has been reported for Desulfomicrobium escambium K11-4 under nitrogen gas conditions. The strain converted $0.54 \mathrm{~mm}$ DBT to unknown products in 3 weeks at $30^{\circ} \mathrm{C}$ with no addition of sulfate. ${ }^{25)}$ Unfortunately, no information is available on whether if the strain degrades aromatic hydrocarbons other than DBT. Microaerobic degradation of carbazole has been reported for eight strains from Bacillus, Serratia, Pseudomonas, and Escherichia but their metabolic pathways are yet unknown. ${ }^{26}$ ) To our best knowledge this is the first report for a pure culture on the effective degradation of various PAHs and HACs under the ELO condition.

16S rRNA gene sequence and a phylogenetic analysis

In order to identify strains $127 \mathrm{~W}$ and T102, the nucleotide sequence of each 16S rRNA gene was analyzed and compared with those of related strains. The homology scores between $127 \mathrm{~W}$ and the most related strains are $97.7 \%$ for $X$. tagetidis and $97.3 \%$ for $X$. autotrophicus. The phylogenetic tree clearly shows that $127 \mathrm{~W}$ is a member of the alpha subclass of

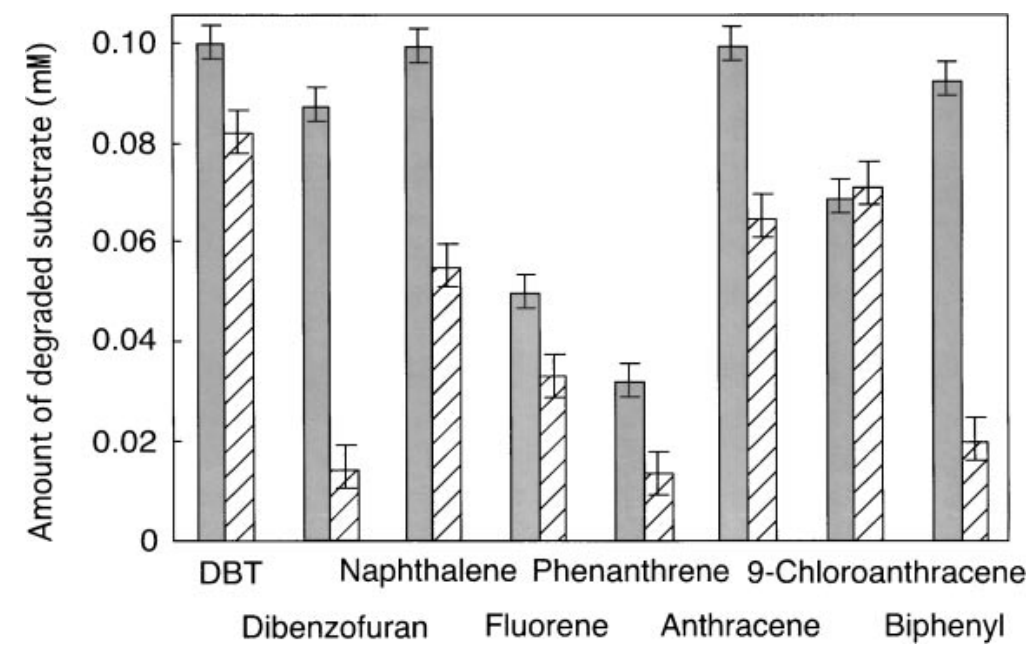

Fig. 3. Degaradation of PAHs and HACs by $127 \mathrm{~W}$.

Various PAHs and HACs at $0.1 \mathrm{~mm}$ were tested for degradation under both aerobic (DO $>7 \mathrm{ppm}$, closed bar) and the ELO (DO $</=0.2 \mathrm{ppm}$, shaded bar) conditions. All the degradation reactions were done at $30^{\circ} \mathrm{C}$ for one week although aerobic degradation was almost completed in a few days. Data are mean values of three independent experiments after subtraction of that with no cell inoculation. The bars indicate S.D. 


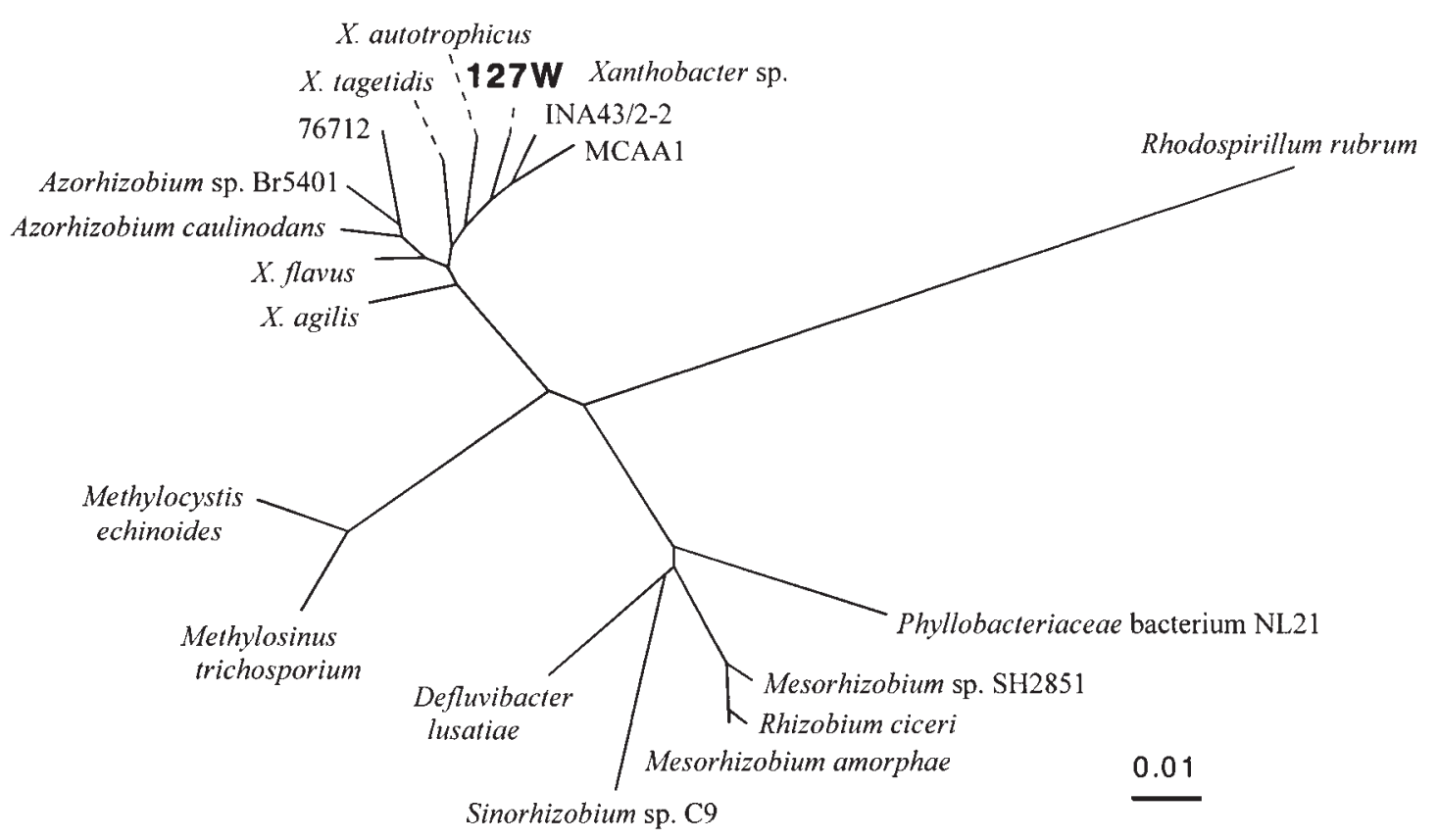

Fig. 4. A Phylogenetic Tree Showing the Relationship between Strain 127W and Other Related Strains.

Only the 16S rRNA sequences with full sequence entry were adopted. The tree was generated by bootstrapping with 1,000 replications. A segment corresponding to an evolutionary distance 0.01 is also shown.

proteobacteria, genus Xanthobacter (Fig. 4). On the other hand, the nucleotide sequence of the $16 \mathrm{~S}$ rRNA gene of T102 was $99.9 \%, 97.6 \%$, and $95.6 \%$ identical to that of Pseudomonas stutzeri, P. flava, and P. aeruginosa, respectively.

\section{Physiological tests}

Physiological characteristics of $127 \mathrm{~W}$ are compared with those of typical Xanthobacter strains (Table 2). They are similarly Gram-negative coccobacilli with no motility and branched cells are formed in the medium containing succinate as a carbon source. Typical bipolar dark spots, presumably reserved polyphosphate, were also observed in the $127 \mathrm{~W}$ cells. Spectroscopic analyses of the methanol extractable pigment of the $127 \mathrm{~W}$ cells showed single absorption peak at $473 \mathrm{~nm}$, indicating that the orange-colored pigment is a zeaxanthine. Zeaxanthine is a popular carotenoide compound produced by Xanthobacter. Carbon dioxide and hydrogen supported the growth of the $127 \mathrm{~W}$ cells as the sole carbon and energy sources, respectively, indicating its autotrophy. Because several Xanthobacter strains are reported to grow chemoautotrophically by the Rubisco pathway, the Rubisco activity was examined according to the method of Chakrabarti et $a .^{27)}$ The results showed that the $127 \mathrm{~W}$ cells had the Rubisco activity (data not shown). On the other hand, all the carbohydrates tested failed to support the growth of $127 \mathrm{~W}$. This poor carbohydrate assimilation ability has also been reported for several oil bacteria. ${ }^{28)}$ The strain uses ethanol, acetic acid, and intermediates in the tricarboxylic acid cycle, such as succinate and fumarate, but does not use malate. The most significant characteristic of $127 \mathrm{~W}$ is the ability to degrade various PAHs and HACs. Aliphatic hydrocarbons and monocyclic aromatic hydrocarbons, such as toluene and benzene, are not degradable by the strain. There are two strains ever reported in the genus Xanthobacter that degrade hydrocarbons. Xanthobacter sp. Py2 is capable of growing on propene, benzene, toluene, and phenol, and its unique alkene monooxygenase has been shown to be responsible for aromatic hydrocarbon degradation. ${ }^{29)}$ Another example is a chlorobenzene degrading X. flavus strain $14 \mathrm{p} 1 .^{30)}$ The unique preference for carbon sources, degradation ability for hydrocarbons, and a distinct position in $16 \mathrm{~S}$ rRNA phylogenetic tree allow us to propose $X$. polyaromaticivorans sp. nov. (Fig. 5).

In contrast to $127 \mathrm{~W}$, strain $\mathrm{T} 102$ had completely the same characteristics as those of the type strain of $P$. stutzeri. They are facultative anaerobes with denitrification activity, motility $(+)$, VP test $(-), \mathrm{H}_{2} \mathrm{~S}$ production $(-)$, oxidase $(+)$, catalase $(+)$, arginine dihydrolase $(-)$, ornithine decarboxylase $(-), \beta$-galactosidase $(-), \beta$ glucosidase $(-)$, urease $(-)$, oxidation of glucose $(+)$, D-mannitol $(+)$, D-mannose $(-)$, maltose $(+)$, gluconate $(+)$, n-capriate $(+)$, adipate $(-)$, malate $(+)$, citrate $(+)$, and growth on MacConkey agar $(+)$. These results allow us to identify strain T102 as P. stutzeri. P. stutzeri XO1 and P16 have been reported to degrade xylene and pyrene, respectively, but both are the studies under aerobic condition. ${ }^{31,32)}$

Description of Xanthobacter polyaromaticivorans sp. nov.

Xanthobacter polyaromaticivorans (po.ly.a..ro.ma. tici'vo.rans. N. L. n. polyaromaticus, polyaromatic 
Table 2. Comparison of Strain $127 \mathrm{~W}$ with Highly Related Xanthobacter Species

\begin{tabular}{|c|c|c|c|}
\hline Characteristics & Strain $127 \mathrm{~W}$ & X. autotrophicus & X. flavus \\
\hline Shape & coccobacilli or rods & coccobacilli or rods & coccobacilli or rods \\
\hline Motility & - & - & - \\
\hline Pleomorphism & + & + & + \\
\hline Zeaxanthin pigment & + & + & + \\
\hline Polyphosphate granules & + & + & + \\
\hline $\mathrm{CO}_{2}$ fixation & + & + & + \\
\hline Nitrogenase & + & + & + \\
\hline Hydrogenase & + & + & + \\
\hline Urease & - & $\mathrm{d}$ & - \\
\hline Oxidase & + & + & + \\
\hline Catalase & + & + & + \\
\hline Tween 80 hydrolysis (Esterase) & + & - & - \\
\hline Nitrate reduction & + & + & + \\
\hline Nitrite reduction & - & - & - \\
\hline $\mathrm{H}_{2} \mathrm{~S}$ production & - & - & - \\
\hline Indole production & - & - & - \\
\hline \multicolumn{4}{|l|}{ Sole carbon source: } \\
\hline $\begin{array}{l}\text { Succinate, Glutamate, Ethanol, } \\
\text { n-Propanol, } \mathrm{CO}_{2}\end{array}$ & + & + & + \\
\hline Acetate, Fumarate, Pyruvate & + & $\mathrm{d}$ & + \\
\hline $\begin{array}{l}\text { Galactose, Lactose, Mannose, } \\
\text { Xylose, Malate, Mannitol, } \\
\text { Sorbitol, Methanol, n-Butanol }\end{array}$ & - & + & + \\
\hline Glucose, Fructose, Sucrose, Citrate & - & $\mathrm{d}$ & + \\
\hline Maltose & - & - & + \\
\hline \multirow[t]{2}{*}{ Main component of fatty acids } & $\begin{array}{l}\text { Hexadecanoic acid } \\
(22.7 \%)\end{array}$ & $\begin{array}{l}\text { 11-octadecenoic } \\
\text { acid }(60-90 \%)\end{array}$ & $\begin{array}{l}\text { 11-octadecenoic } \\
\text { acid }(60-90 \%)\end{array}$ \\
\hline & $\begin{array}{l}\text { Octadecanoic acid } \\
(10.6 \%)\end{array}$ & & \\
\hline Growth temperature (opt, ${ }^{\circ} \mathrm{C}$ ) & $15-37(30)$ & $15-37(30)$ & $15-37(30)$ \\
\hline $\mathrm{Mol} \% \mathrm{GC}$ & 65 & $65-70$ & $68-69$ \\
\hline
\end{tabular}

+ , positive; - , negative; d, 11 89\% of the strains are positive.

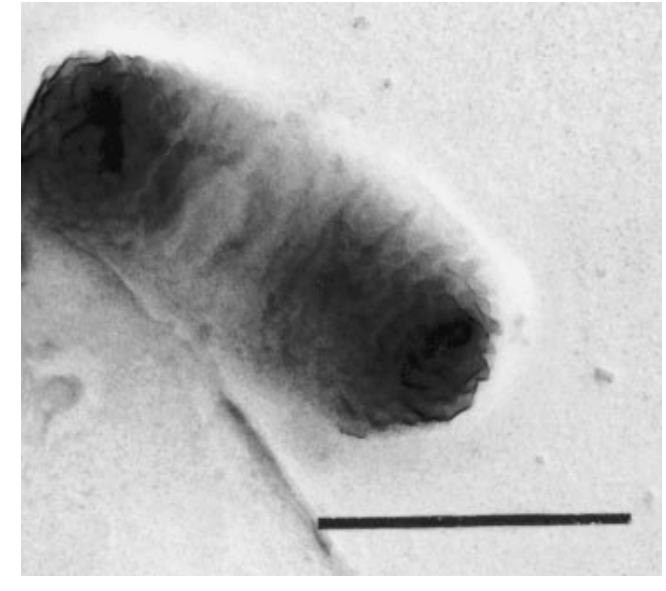

Fig. 5. Scanning Electron Microscopy of Strain 127W.

Cells were grown in $\mathrm{L}$ broth at $30^{\circ} \mathrm{C}$. The bar indicates the size of $1 \mu \mathrm{m}$.

compound; L. part. vorans, eating; polyaromaticivorans, eating polyaromatic compounds) is a Gram-negative, encapsulated facultative anaerobic organism. Cells are mostly cocco-bacilli but occasionally branched forms. No motility. Colonies are mucoidy with light orange to pink color probably due to zeaxanthine. It degrades a wide range of polycyclic aromatic hydrocarbons and heterocyclic aromatic compounds such as anthracene, fluorene, naphthalene, phenanthrene, dibenzothiophene, dibenzofuran, and biphenyl. It does not assimilate carbohydrates such as glucose, galactose, sucrose, maltose, mannose, xylose, mannitol, sorbitol, lactose, or fructose. Growth temperature is between 25 and $37^{\circ} \mathrm{C}$ (optimally at $30^{\circ} \mathrm{C}$ ). The mol\% GC of the DNA is $65 \%$.

\section{Acknowledgment}

This work was supported by a grant from the Program for Promotion of Basic Research Activities for Innovative Biosciences (PROBRAIN). The authors acknowledge to Dr. Juan Wiegel (University of Georgia) for helpful suggestions on the characterization of $127 \mathrm{~W}$.

\section{References}

1) La Vose, E. I., Hecht, S. S., Bedenko, V., and Hoffman, D., Identification of the mutagenic metabolites of fluorene, 2-methylfluorene, and 3-methyl-fluoranthene. Carcinogenesis, 3, 841-846 (1982).

2) Menzie, C. A., Potocki, B. B., and Santodonato, J., Exposure to carcinogenic PAHs in the environment. Environ. Sci. Technol., 26, 1278-1284 (1992).

3) Sutherland, J. B., Rafii, F., Khan, A. A., and Cerniglia, 
C. E., Mechanisms of polycyclic aromatic hydrocarbon degradation. In "Microbial Transformation and Degradation of Toxic Organic Chemicals", eds. Young, L. Y., and Cerniglia, C. E., John Wiley and Sons, Inc., New York, pp. 269-306 (1995).

4) Kanaly, R. A., and Harayama, S., Biodegradation of high-molecular-weight polycyclic aromatic hydrocarbons by bacteria. J. Bacteriol., 182, 2059-2067 (2000).

5) Cameron, M. D., Timofeevski, S., and Aust, S. D., Enzymology of Phanerochaete chrysosporium with respect to the degradation of recalcitrant compounds and xenobiotics. Appl. Microbiol. Biotechnol., 54, 751758 (2000).

6) Cerniglia, C. E., Biodegradation of polycyclic aromatic hydrocarbons. Curr. Opin. Biotechnol., 4, 331-338 (1993).

7) Rockne, K. J., Chee-Sanford, J. C., Sanford, R. A., Hedlund, B. P., Staley, J. T., and Strand, S. E., Anaerobic naphthalene degradation by microbial pure cultuers under nitrate-reducing conditions. Appl. Environ. Microbiol., 66, 1595-1601 (2000).

8) Schwarzenbach, R. P., and Westall, J., Transport of nonpolar organic compounds form surface water to ground water laboratory sorption studies. Environ. Sci. Technol., 15, 1360-1367 (1981).

9) Davies, J. I., and Evans, W. C., Oxidation metabolism of naphthalene by soil pseudomonad: the ring-fission mechanism. Biochem. J., 91, 251-261 (1964).

10) Kiyohara, H., Nagao, K., and Yano, K., Rapid screen for bacteria degrading water-insoluble, solid hydrocarbons on agar plates. Appl. Environ. Microbiol., 43, 454-457 (1982).

11) Morikawa, M., Kanemoto, M., and Imanaka, T., Biological oxidation of alkane to alkene under anaerobic conditions. J. Ferment. Bioeng., 82, 309-311 (1996).

12) Kato, T., Haruki, M., Imanaka, T., Morikawa, M., and Kanaya, S., Isolation and characterization of long-chainalkane degrading Bacillus thermoleovolans from deep subterranean petroleum reservoirs. J. Biosci. Bioeng., 91, 64-70 (2001).

13) Sambrook, J., and Russel, D. W., Molecular cloning: A laboratory manual, CSHL Press, Cold Spring Harbor, NY (2001).

14) Page, R. D. M., Tree view: an application to display phylogenetic trees on personal computers. Comp. Appl. Biosci., 12, 357-358 (1996).

15) Thompson, J. D., Higgins, D. G., and Gibson, T. J., CLUSTAL W: improving the sensitivity of progressive multiple sequence alignment through sequence weighting, position-specific gap penalties and weight matrix choice. Nucleic Acids Res., 22, 4673-4680 (1994).

16) Krieg, N. R., and Holt, J. G., Bergey's manual of systematic bacteriology, Vol. 1, Williams and Wilkins, Baltimore, MD (1984).

17) Tamaoka, J., and Komagata, K., Determination of DNA base composition by reverse-phase high-performance liquid chromatography. FEMS Microbiol. Lett., 25, 125128 (1984).

18) Kropp, K. G., Saftic, S., Andersson, J. T., and Fedorak, P. M., Transformations of six isomers of dimethylbenzothiophene by three Pseudomonas strains. Biodegradation, 7, 203-221 (1996).
19) Kodama, K., Umehara, K., Shimizu, S., Nakatani, Y., Minoda, Y., and Yamada, K., Identification of microbial products from dibenzothiophene and its proposed oxidation pathway. Agric. Biol. Chem., 37, 45-50 (1973).

20) Annweiler, E., Michaelis, W., and Meckenstock, R., Anaerobic cometabolic conversion of benzothiophene by a sulfate-reducing enrichment culture and in a taroil-contaminated aquifer. Appl. Environ. Microbiol., 67, 5077-5083 (2001).

21) Heider, J., and Fuchs, G., Anaerobic metabolism of aromatic compounds. Eur. J. Biochem., 243, 577-596 (1997).

22) Coates, J. D., Woodward, J., Allen, J., Philp, P., and Lovley, D. R., Anaerobic degradation of polycyclic aromatic hydrocarbons and alkanes in petroleum-contaminated marine harbor sediments. Appl. Environ. Microbiol., 63, 3589-3593 (1997).

23) Zhang, X., and Young, L. Y., Carboxylation as an initial reaction in the anaerobic metabolism of naphthalene and phenanthrene by sulfidogenic consortia. Appl. Environ. Microbiol., 63, 4759-4764 (1997).

24) Eriksson, M., Sodersten, E., Yu, Z., Dalhammar, G., and Mohn, W. W., Degradation of polycyclic aromatic hydrocarbons at low temperature under aerobic and nitrate-reducing conditions in enrichment cultures from northern soils. Appl. Environ. Microbiol., 69, 275-284 (2003).

25) Onodera-Yamada, K., Morimoto, M., and Tani, Y., Degradation of dibenzothiophene by sulfate-reducing bacteria cultured in the presence of only nitrogen gas. $J$. Biosci. Bioeng., 91, 91-93 (2001).

26) Kobayashi, T., Kurane, R., Nakajima, K., Nakamura, Y., Kirimura, K., and Usami, S., Isolation of bacteria degrading carbazole under microaerobic conditions, i.e. nitrogen gas substituted conditions. Biosci. Biotechnol. Biochem., 59, 932-933 (1995).

27) Chakrabarti, S., Bhattacharya, S., and Bhattacharya, S. K., A nonradioactive assay method for determination of enzymatic activity of D-ribulose-1,5-bisphosphate carboxylase/oxygenase (Rubisco). J. Biochem. Biophys. Meth., 52, 179-187 (2002).

28) Kanamori, T., Rashid, N., Morikawa, M., Atomi, H., and Imanaka, T., Oleomonas sagaranensis gen. nov., sp. nov., represents a novel genus in the alpha-proteobacteria. FEMS Microbiol. Lett., 217, 255-261 (2002).

29) Zhou, N.-Y., Jenkins, A., Chan Kwo Chion C. K., and Leak, D. J., The alkene monooxygenase from Xanthobacter strain Py2 is closely related to aromatic monooxygenase and catalyzes aromatic monohydroxylation of benzene, toluene, and phenol. Appl. Environ. Microbiol., 65, 1589-1595 (1999).

30) Spiess, E., Sommer, C., and Gorisch, H., Degradation of 1,4-dichlorobenzene by Xanthobacter flavus 14p1. Appl. Environ. Microbiol., 61, 3884-3888 (1995).

31) Baggi, G., Barbieri, P., Galli, E., and Tollari, S., Isolation of a Pseudomonas stutzeri strain that degrades o-xylene. Appl. Environ. Microbiol., 53, 2129-2132 (1987).

32) Kazunga, C., and Aitken, M. D., Products from the incomplete metabolism of pyrene by polycyclic aromatic hydrocarbon-degrading bacteria. Appl. Environ. Microbiol., 66, 1917-1922 (2000). 